\title{
INTERCEPTAÇÃO DAS CHUVAS EM UM FRAGMENTO DE FLORESTA DA MATA ATLÂNTICA NA BACIA DO PRATA, RECIFE, PE ${ }^{1}$
}

Albert Einstein Spindola Saraiva de Moura ${ }^{2}$, Marcus Metri Correa ${ }^{3}$, Elcides Rodrigues da Silva ${ }^{4}, \mathrm{Rinaldo}^{2}$ Luiz Caraciolo Ferreira ${ }^{5}$, Adriana de Carvalho Figueiredo ${ }^{2}$ José Marcelo Cordeiro Possas ${ }^{2}$

\begin{abstract}
RESUMO - A mata de Dois Irmãos é uma das poucas áreas remanescentes da Floresta Atlântica no Estado de Pernambuco. Nela estão inseridos os açudes do Meio, do Prata e Dois Irmãos que compõem a bacia hidrográfica do Prata. Este trabalho teve como objetivo estudar a partição das chuvas em um fragmento de Floresta Atlântica na Bacia do Prata em Recife, PE. Para obtenção dos dados de precipitação sob florestas, foram instalados 24 interceptômetros e selecionadas 20 árvores do estrato superior, e 10 árvores do sub-bosque foram escolhidas para obter os dados de escoamento pelo tronco. Encontraram-se perdas por interceptação de 208,3 mm, precipitação efetiva de 1.431,7 mm, precipitação interna de 1.392,4 mm, escoamento pelo tronco das árvores do estrato superior de $6,6 \mathrm{~mm}$ e escoamento pelo sub-bosque de $32,8 \mathrm{~mm}$, correspondendo a $12,7 \%, 87,3 \%, 84,9 \%$, $0,4 \%$ e $2 \%$, respectivamente, do total precipitado de $1.464 \mathrm{~mm}$.
\end{abstract}

Palavras-chave: Precipitação efetiva, precipitação interna e escoamento pelo tronco.

\section{RAINFALL INTERCEPTION IN AN ATLANTIC FOREST FRAGMENT IN THE PRATA BASIN, RECIFE, PE}

\begin{abstract}
The Dois Irmãos forest is one of the few remaining areas of the Atlantic Forest in the State of Pernambuco. The dams of Meio, Prata and Dois Irmãos, which belong to the Prata Basin, are in it. The objective of this work was to study the rainfall partitioning in a fragment of the Atlantic forest in the Prata basin, in Recife, PE. 24 raingouges were installed in the interior of the forest to measure the throughfall and 20 trees of superior extract and 10 of the sub-forest were selected to determine the stemflow. The results showed values of loss interception of 208,3 mm, net precipitation of 1431,7 mm, throughfall of 1392,4 mm, stemflow by superior stratum of 6,6 mm and stemflow by sub-forest of 32,8 $\mathrm{mm}$, corresponding to 12,7\%, $87,3 \%, 84,9 \%, 0,4 \%$ and $2 \%$, respectively.
\end{abstract}

Keywords: Net precipitation, throughfall and stemflow.

\section{INTRODUÇÃO}

A cobertura florestal tem grande importância dentro do contexto do balanço hídrico de determinado local e pode alterar o mecanismo de entrada de água na superfície do solo. O formato da cobertura vegetal, a área foliar e a estrutura da casca são considerados fatores-chave para se determinar a capacidade de armazenamento de água no dossel, afetando a interceptação das chuvas e os demais componentes do balanço hídrico local. O tipo, extensão e condições de vegetação exercem marcada influência nos modelos de deposição e quantidade das precipitações pluviais que alcançam a superfície do solo. Então, toda modificação de uma cobertura florestal decorrente da intervenção

\footnotetext{
${ }^{1}$ Recebido em 17.08.2007 e aceito para publicação em 24.04.2009.

${ }^{2}$ ProgramadePós-GraduaçãoemEngenhariaAgrícolada UniversidadeFederal Rural dePernambuco(UFRPE).E-mail: <aessmoura@yahoo.com.br> . ${ }^{3}$ Departamento de Tecnologia Rural da UFPE. E-mail: <metri@ dtr.ufrpe.br>.

${ }^{4}$ ProgramadePós-GraduaçãoemAgronomiada UniversidadeEstadual PaulistaJúliode MesquitaFilho(UNESP).E-mail: <rodagro@hotmail.com>.

${ }^{5}$ Departamento de Ciência Florestal da UFRPE. E-mail:<rinaldo@dcfl.ufrpe.br>.
} 
do homem ou do seu desenvolvimento natural afeta a quantidade de água que chega ao solo e sua reserva (HUBER e OYARZÚN, 1992; GASH et al., 1995; VAN DIJK e BRUIJNZEEL, 2001). Outro fator que deve ser levado em consideração na interceptação é a característica das chuvas. Nalon e Vellardi (1993) verificaram que em um período caracterizado por apresentar chuva de baixa magnitude, intensidade e frequiência foi registrado maior taxa de interceptação.

Uma das principais influências da floresta ocorre já no recebimento das chuvas pelas copas das árvores, quando se dá o primeiro fracionamento da água, em que parte é temporariamente retida pela massa vegetal e, em seguida, evaporada para a atmosfera, processo denominado interceptação. O restante alcança o solo por precipitação interna ou pelo escoamento de água pelo tronco das árvores (ARCOVA et al., 2003), em que a soma desses dois processos é denominado precipitação efetiva.

O conhecimento do tamanho de cada uma das três frações na partição das chuvas, interceptação, precipitação interna e escoamento pelo tronco será um complemento indispensável para se obter valor preciso do balanço hídrico numa floresta (JIMÉNEZ et al., 1996). A quantidade de água envolvida nesses três processos é variável e depende de fatores relacionados tanto com a vegetação quanto pelas condições climáticas na qual a floresta está inserida (LEOPOLDO e CONTE, 1985). Por isso são necessários estudos particulares de cada situação exclusiva. Fatores experimentais também influenciam os resultados encontrados nos estudos desses processos, dificultando a comparação de resultados entre os locais (CASTRO et al., 1983).

Na tentativa de estimar a interceptação, modelos foram propostos. Em 1979, Gash propôs um modelo de interceptação de chuva que é essencialmente uma forma analítica do modelo de Rutter (RUTTER et al., 1975). O modelo de Gash demonstrou que a evaporação da chuva interceptada pode ser estimada pela estrutura florestal, evaporação média, taxa de chuva e chuvapadrão. Embora alguns pesquisadores tenham obtido sucesso com seu uso, na teoria o modelo superestima a perda por interceptação em florestas escassas. Por conta dessa deficiência, Gash et al. (1995) e Valente et al. (1997), respectivamente, revisaram o modelo original para aplicação nessas florestas (ZHANG et al., 2006).
Apesar da grande importância que uma floresta exerce dentro do contexto do balanço hídrico local, ainda são poucos os estudos sobre a partição das chuvas por floresta de Mata Atlântica (ARCOVA, 2003).

Em Pernambuco, uma das poucas áreas remanescentes da floresta atlântica é a Mata de Dois Irmãos, na qual está inserida a Bacia Hidrográfica do Prata, composta pelos Açudes Dois Irmãos, do Meio e do Prata, que são utilizados para reforço ao abastecimento público de água da cidade do Recife, Horto de Dois Irmãos e para área de lazer e zoológico. Esses reservatórios são favorecidos pela mata nativa, que atua no ciclo hidrológico de maneira mais significativa que outros ecossistemas vegetais, pois proporcionam melhores condições de infiltração da água da chuva no solo, contribuindo para diminuir a variação da vazão ao longo do ano, além do retardamento dos picos de cheia.

Jetten (1996) afirmou que, quando o balanço hídrico de uma floresta é descrito, a interceptação não pode ser tratada como uma fração que é simplesmente subtraída da precipitação, mas os fluxos de água associados com os processos de umedecimento e secagem têm de ser quantificados.

Assim, este estudo tem como objetivo estudar a partição das chuvas em um fragmento de floresta atlântica na Bacia do Prata em Recife, PE.

\section{MATERIAL E MÉTODOS}

O experimento foi desenvolvido em uma parcela experimental de $3.000 \mathrm{~m}^{2}$ durante o período de maio de 2006 a janeiro de 2007, na Bacia do Prata, localizada entre as coordenadas 286.000 E, 9.113.000 S e 284.000 E, 9.116.000 S. A bacia apresenta três reservatórios superficiais, conhecidos como açudes do Meio, do Prata e Dois Irmãos. De acordo com Silvestre et al. (1998), apesar da pressão exercida pela população urbana nos seus arredores, constitui-se num dos remanescentes da Mata Atlântica do Estado de Pernambuco, com estrato arbóreo denso formando um dossel que atinge $20 \mathrm{~m}$ de altura, sendo considerada mata primária e, ou, mata em estado avançado de regeneração, tratando-se de área de preservação ambiental, rica em biodiversidade. De acordo com a classificação de Köppen, o clima do local enquadra-se no tipo As', denominado tropical quenteúmido com temperatura anual média de $25,4^{\circ} \mathrm{C}$, precipitação média anual de $2.457 \mathrm{~mm}$, com chuvas de outono-inverno (INMET, 1992). 
Muitas espécies vegetais são encontradas na Bacia do Prata (ver SILVESTRE et al., 1998), das quais foram usadas na quantificação do escoamento de água de chuva pelo tronco as seguintes: Cabelo de cutia (Banara nítida); Visgueiro (Parkia pendula (Willd.) Benth. Ex walp.); cupiúba-vermelha (Goupia glabra Aubl); amescla-de-cheiro (Protium heptaphyllum March); conduru (Brosimum paraense Huber); imbiriba (Eschweilera ovata Miers); laranjinha (Casearia gossypiospermum Rehder); Quiri (Brosimum discolor Schott); cabatan-de-leite (Thyrsodium spruceanum Benth); sambaqui (Schefflera morototoni (Aubl.) maguire); sabiazeira (Miconia ferruginata $\mathrm{DC}$ ); cocão (Pogonophora schomburgkiana Miers); e camboatande-rego (Cupania revoluta $\mathrm{Radlk})$.

A precipitação total foi determinada por meio da utilização de um pluviógrafo automático, instalado na estação experimental da Universidade Federal Rural de Pernambuco (UFRPE) em local aberto, a uma distância de aproximadamente $1.200 \mathrm{~m}$ da parcela experimental.

Para a determinação da precipitação interna, foram utilizados 24 interceptômetros, construídos com tubos de PVC de 100 mm de diâmetro e área de captação igual a 78,54 cm². Os interceptômetros foram instalados no interior da Mata Atlântica, obedecendo a um espaçamento de $10 \mathrm{~m}$, nivelados e colocados a uma altura de 1,50 $\mathrm{m}$ do solo. Após cinco coletas consecutivas, mudouse a posição de cada interceptômetro em $1 \mathrm{~m}$, no sentido horário, de modo que cada um ocupou quatro pontos diferentes (Figura 1).

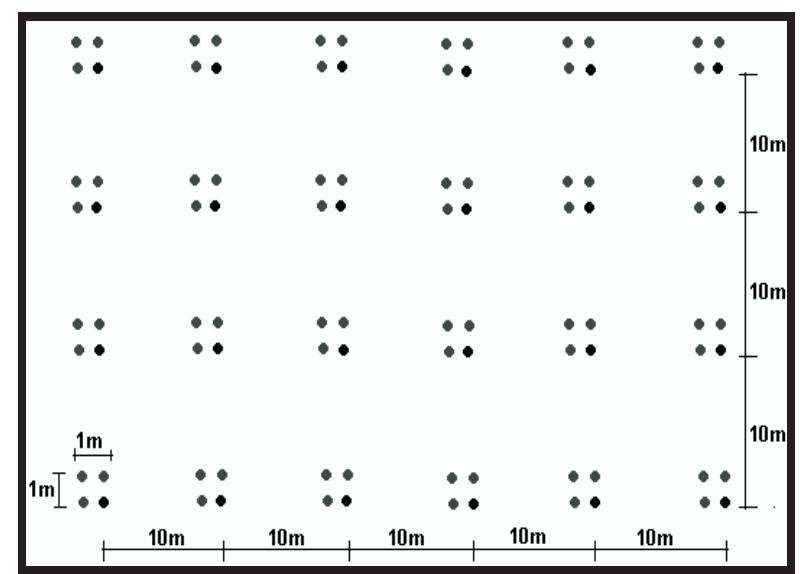

Figura 1 - Distribuição dos pluviômetros na área experimental. Figure 1-Distribution of the raingouges in the experimental area.
Para a quantificação do escoamento pelo tronco foram selecionadas 20 árvores, sendo essas as mais altas e com o diâmetro a 1,30 m do solo (DAP) acima de $20 \mathrm{~cm}$, as quais foram envolvidas por um segmento de mangueiras plásticas de $3 / 4$ de polegadas, cortadas no sentido longitudinal, constituindo-se em calhas coletoras do montante escoado. As calhas foram fixadas sob a forma de espiral, acompanhando a circunferência dos troncos das árvores, onde a vedação do contato mangueira-tronco deu-se por meio da utilização de massa adesiva própria para calafetação (LIMA, 1976; LEOPOLDO e CONTE, 1985; LIMA, 1998).

De posse do volume de precipitação armazenado, determinou-se a lâmina média escoada pelo tronco através da relação entre o volume total escoado e o somatório das áreas de captação das 20 árvores. Para determinar a área de captação, estimou-se a projeção vertical da copa de cada árvore ao solo, traçando-se pelo menos quatro linhas passando pelo tronco (eixo) até as extremidades da projeção, perpendiculares entre si, duas a duas, de forma que a área total de captação foi obtida pelo somatório das áreas triangulares geradas pela ligação entre os pontos extremos das linhas (MARIN et al., 2000). Na Figura 2 é mostrado o esboço de duas projeções verticais divididas em subáreas triangulares.

A superfície total de captação de chuva da área estuda foi obtida pela equação 1 .

$$
A_{\text {Total }}=\sum_{i=1}^{20} A_{\text {Arv }}
$$

em que:

$$
\begin{aligned}
& \mathrm{A}_{\text {Total }}=\text { área total de captação }\left(\mathrm{m}^{2}\right) ; \mathrm{e} \\
& \mathrm{A}_{\mathrm{Arv}}=\text { área de captação de cada árvore }\left(\mathrm{m}^{2}\right) .
\end{aligned}
$$

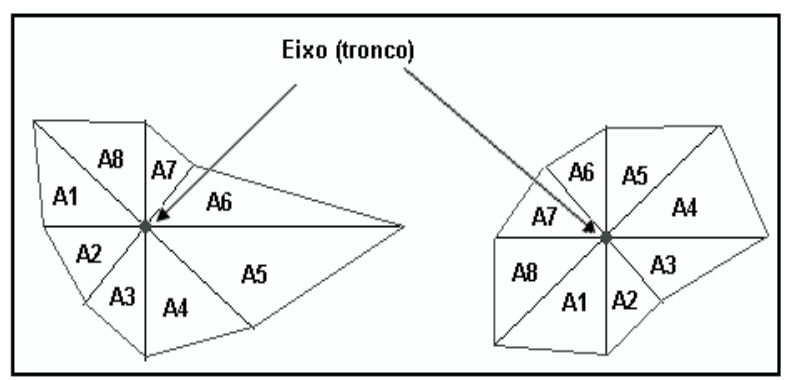

Figura 2 - Projeção vertical da copa de duas árvores divididas em subáreas.

Figure 2 - Canopy vertical projection of two trees divided in sub areas.

R. Árvore, Viçosa-MG, v.33, n.3, p.461-469, 2009 
Para quantificar o escoamento pelo sub-bosque (Esc SB), utilizaram-se 10 árvores de menor porte, com diâmetro a $1,30 \mathrm{~m}$ do solo (DAP) acima de $5 \mathrm{~cm}$ e menor que $20 \mathrm{~cm}$ e altura superior aos interceptômetros, variando de 2,0 a 3,5 m. Na construção do sistema coletor, usouse massa durepox, fixando-a ao redor do tronco, constituindo um formato de concha. A lâmina escoada foi determinada seguindo-se a mesma metodologia usada na determinação da lâmina escoada pelas árvores do estrato superior.

Após a obtenção dos dados, procedeu-se à estimativa das perdas por interceptação empregando a equação utilizada por Lima (1998) com modificações e considerando o escoamento no sub-bosque (equação 2).

$$
\mathrm{I}=\mathrm{PT}-(\mathrm{PT}+\mathrm{Esc} \mathrm{Tr}+\mathrm{Esc} \mathrm{SB})
$$

em que:

$$
\begin{aligned}
& \mathrm{I}=\text { perda por interceptação }(\mathrm{mm}) ; \\
& \mathrm{PT}=\text { precipitação total }(\mathrm{mm}) ; \\
& \mathrm{PI}=\text { precipitação interna }(\mathrm{mm}) ; \\
& \text { Esc Tr = escoamento pelo tronco }(\mathrm{mm}) ; \mathrm{e} \\
& \text { Esc SB = escoamento pelo sub-bosque }(\mathrm{mm}) .
\end{aligned}
$$

\section{RESULTADOS E DISCUSSÃO}

Durante o período de estudo foram registrados 1. $640 \mathrm{~mm}$ de chuva, com variação de 1 a $147 \mathrm{~mm}$. No entanto, observou-se em alguns eventos que a precipitação interna média foi superior à precipitação total, o que em tese seria impossível de acontecer devido à interceptação das chuvas promovida pela cobertura florestal, porque parte da precipitação total é evaporada e parte atinge o solo através do escoamento pelo tronco e gotejamento. Na Tabela 1 estão apresentados os eventos de precipitação interna média que superaram a precipitação total.

Tabela 1- Eventos de precipitação interna (PI) que superaram a precipitação total (PT)

Table 1-Events of Throughfall (PI) bigger than the gross rainfall $(P T)$

\begin{tabular}{ccc}
\hline PT $(\mathrm{mm})$ & PI $(\mathrm{mm})$ & $\%$ \\
\hline 92,5 & 98,7 & 6,8 \\
27,2 & 31,1 & 14,5 \\
11,2 & 12,5 & 12,2 \\
147,6 & 150,8 & 2,2 \\
5,1 & 6,2 & 21,1 \\
3,6 & 3,7 & 4,2 \\
\hline
\end{tabular}

R. Árvore, Viçosa-MG, v.33, n.3, p.461-469, 2009
A distância e a diferença de altitude entre a parcela experimental e o pluviógrafo automático podem ter contribuído para tal ocorrência, devido à variabilidade espacial das chuvas. Bega et al. (2005), com altitudes e distâncias variando de 29 a 57 m e 257 a 3.900 m, respectivamente, constataram redução do coeficiente de correlação dos dados de chuva à medida que a distância entre os dois pontos aumentou. Os mesmos autores afirmaram que efeito provocado pela diferença de altitude é maior que o efeito provocado pela distância entre os pluviômetros num mesmo nível. Camargo et al. (1999), verificando os dados diários de precipitação pluvial de 19 estações meteorológicas, também observaram alta variabilidade espacial das chuvas, visto os baixos valores do coeficiente de determinação. Outro fator importante é a desuniformidade da cobertura vegetal. A ocorrência de diferentes espécies na área e o entrelaçamento entre seus galhos contribuem para que o fluxo de escoamento ocorra por caminhos preferenciais, gerando pontos de gotejamento e áreas protegidas, que tendem a aumentar a contribuição de chuva em alguns interceptômetros e a diminuir em outros, respectivamente. Neal et al. (1991) verificaram que, além da estrutura florestal, a variabilidade pode ocorrer devido, dentro e entre chuvas, à irregularidade da topografia, margem geométrica da floresta, tamanho e espaçamento das árvores.

Quando os interceptômetros foram analisados individualmente, observou-se que aproximadamente $35 \%$ armazenaram uma lâmina de chuva maior que a precipitação total incidente. Na Figura 3 é mostrada a distribuição das chuvas, em percentagem, no interior da malha retangular delimitada pelos interceptômetros.

Nota-se que existe alta variabilidade da precipitação interna média relativa nos diferentes interceptômetros, com amplitude de 50 a $115 \%$. Da mesma forma que ocorreu aumento da precipitação interna proveniente, provavelmente, do fluxo concentrado que gotejou diretamente nos interceptômetros, por outro lado ocorreu diminuição da lâmina coletada em alguns interceptômetros. Isso talvez possa ser justificado pelo fato de as maiores depressões, observadas na Figura 3, ocorrerem sempre próximas aos picos, o que leva a crer que a água que deveria atingir os locais onde estão as depressões percorreu caminhos preferenciais, atingindo os locais onde estaram situados os picos. 


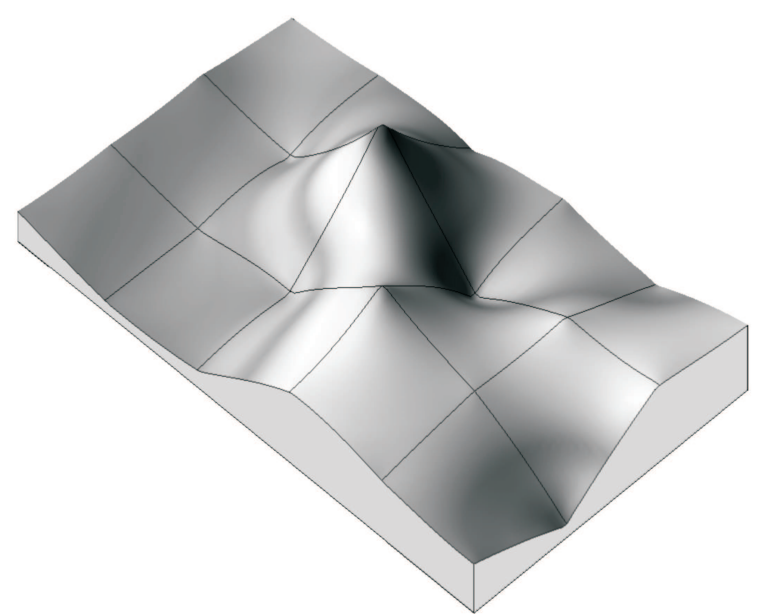

Figura 3 - Variabilidade espacial da precipitação interna (\%) na parcela experimental.

Figure 3 - Spatial variability of Throughfall (\%) in the experimental plot.

Dos 24 interceptômetros foram realizadas 704 coletas de precipitação interna, das quais, se fez a distribuição de frequência. Na Figura 4 é mostrada a distribuição de frequência da precipitação interna relativa à precipitação total.

Verificou-se que em aproximadamente $30 \%$ das coletas a precipitação interna foi superior à precipitação total e $40 \%$ corresponderam a um valor relativo menor que $70 \%$. As coletas apresentaram coeficiente de variação de aproximadamente $34 \%$. Essa variação pode ser reduzida com a instalação de mais interceptômetros, para diminuir o espaçamento entre eles na malha de $150 \mathrm{~m}^{2}$, ou aumentando a sua frequência de rotação. Esses valores reforçam ainda mais as considerações de Kellman e Roulet (1990), que indicaram a necessidade de se implantar grande número de interceptômetros e movimentá-los dentro da área estudada, a fim de minimizar o erro provocado pelas condições adversas.

Os dados de precipitação interna, escoamento pelo tronco e escoamento pelo sub-bosque, submetidos à análise de regressão, encontram-se nas Figuras 5, 6 e 7 , respectivamente.

De acordo com a análise de regressão, aproximadamente $99 \%, 94 \%$ e $85 \%$ dos dados de precipitação interna, escoamento pelo tronco e escoamento pelo sub-bosque, respectivamente, puderam ser explicados pela precipitação total. Todos os processos avaliados apresentaram alta correlação com a precipitação total. O contrário ocorreu com a interceptação que apresentou baixa correlação com a precipitação total. Notou-se também que alguns eventos de chuva de mesma magnitude tiveram resultados distintos de precipitação interna, escoamento pelo tronco do estrato superior e sub-bosque. Essa variação talvez possa ser justificada pela interferência de outros fatores, como: intensidade de chuva, grau de umidade da cobertura, velocidade do vento, característica da vegetação e intervalo entre chuvas. Aston (1979), Jordan e Heuvelop (1981), Lima (1981), Leopoldo e Conte (1985), Singh (1987) e Neal et al. (1993), citados por Lima (1998), constataram que a partição da chuva em uma cobertura florestal não pode ser considerada proporção constante da precipitação local durante todo o ano. Arcova et al. (2003), estudando uma Floresta Atlântica no Estado de São Paulo, observaram variação na correlação desses processos quando consideraram os períodos chuvoso e pouco chuvosos, sendo mais acentuada na interceptação. No entanto, os autores observaram que a variação foi mais acentuada na interceptação, onde os valores de $\mathrm{R}^{2}$ encontrados foram, respectivamente, 0,8117 e 0,5806 nos períodos chuvosos e pouco chuvosos.

A partição das chuvas em precipitação interna (PI), escoamento pelo tronco (Esc Tr), escoamento pelo sub-bosque (Esc SB), precipitação efetiva (PE) e interceptação (I) está apresentada na Tabela 2.

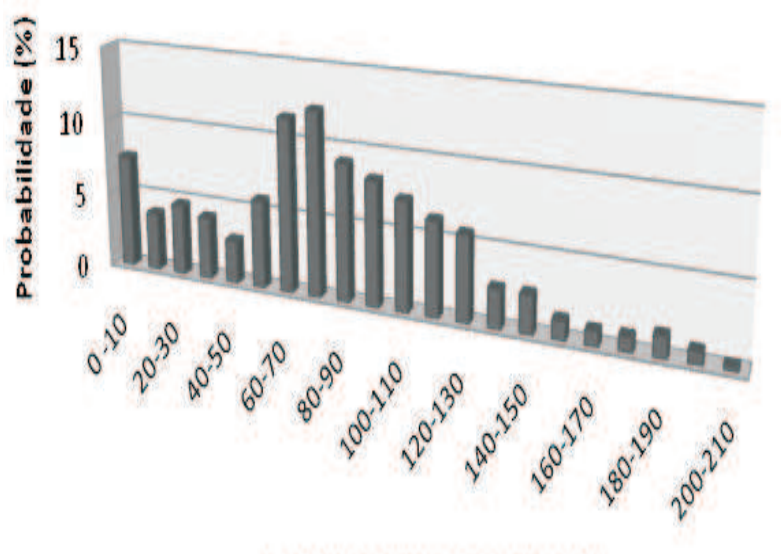

Precipitação interna relativa $(\%)$

Figura 4 - Distribuição de frequência da precipitação interna relativa.

Figure 4-Frequency distribution of the relative throughfall.

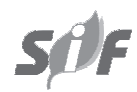

R. Árvore, Viçosa-MG, v.33, n.3, p.461-469, 2009 


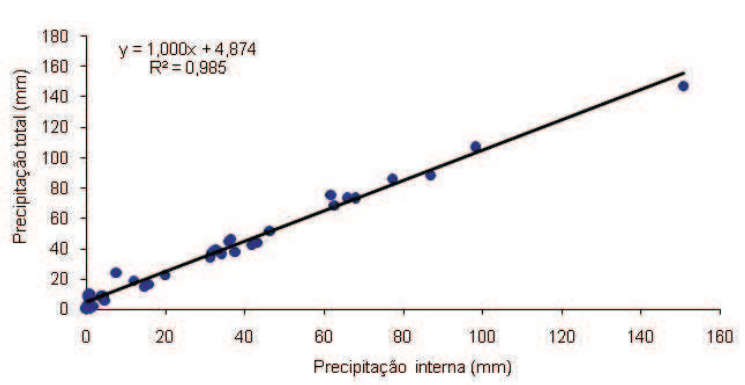

Figura 5 - Relação entre a precipitação total e a precipitação interna.

Figure 5-Gross rainfall and throughfall relation.

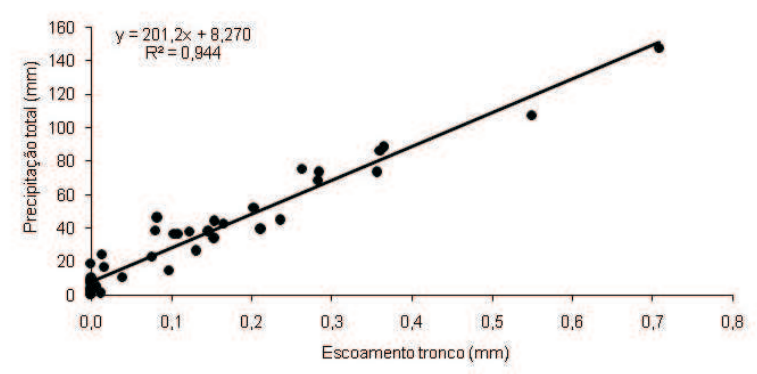

Figura 6 - Relação entre a precipitação total e o escoamento pelo tronco.

Figure 6 - Gross rainfall and stemflow relation.

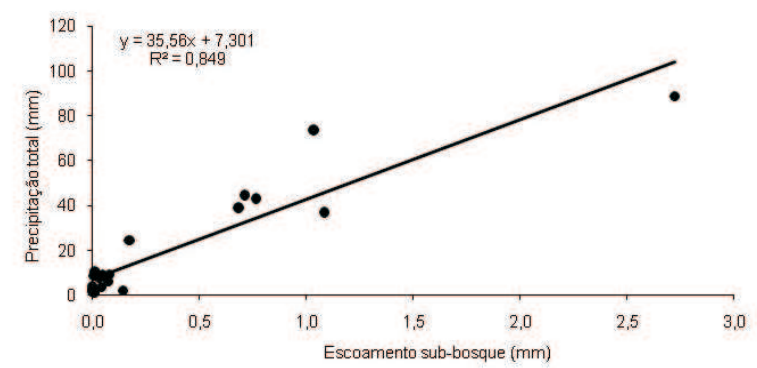

Figura 7- Relação entre a precipitação total e o escoamento pelo sub-bosque.

Figure 7- Gross rainfall and stemflow by sub forest relation.

Os valores de precipitação interna e escoamento pelo tronco observados neste estudo foram semelhantes aos apresentados por Arcova et al. (2003), 81,2\% e $0,2 \%$, respectivamente. Esses autores constataram que a interceptação foi igual a $18,6 \%$ da precipitação total, sendo superior ao obtido neste estudo. Esse fato pode ter ocorrido porque foram utilizadas apenas as árvores com diâmetro superior a $10 \mathrm{~cm}$. No entanto, vegetais com diâmetro inferior a $10 \mathrm{~cm}$ poderiam estar acima dos interceptômetros, superestimando a interceptação, uma vez que tal escoamento não foi levado em consideração no cálculo da precipitação efetiva. Portanto, haveria redução no valor da interceptação que, por sua vez, se aproximaria mais do valor observado nesta pesquisa. Dietz et al. (2006) também apresentaram escoamento pelo tronco semelhante, com valor menor que $1 \%$ da precipitação total, e precipitação interna inferior com percentual de $70 \%$. Percentual semelhante de precipitação interna também foi observado por Oliveira Junior e Dias (2005), que obtiveram valor de 80\%, e por Ferreira et al. (2005), com valores que variaram de 74,2 a 87,1\%. A mesma semelhança não foi verificada por Lima (1998) e Dietz et al. (2006), que encontraram valores de $61,5 \%$ e $70 \%$, respectivamente.

Quando foram comparados os percentuais de escoamento pelo tronco, notaram-se valores superiores, obtidos por Oliveira Junior e Dias (2005) e Lima (1998), correspondentes a 1,7 e 0,9\%, respectivamente. Apesar de esses valores serem maiores, eles ainda representam parcela muito pequena do total precipitado. Esses mesmos autores observaram interceptação superior à deste estudo, igual a 18,3 e $37,6 \%$, respectivamente. Os diferentes resultados ocorrem porque cada ecossistema tem sua característica particular, e isso diferencia cada processo de interceptação. De modo geral, os resultados deste trabalho encontramse dentro da margem dos obtidos na literatura.

Vale ressaltar, nesse momento, que o escoamento pelo tronco representa parcela muito pequena da precipitação total quando comparado com os outros parâmetros. Esse valor, apesar de parecer insignificante, promove distribuição localizada da precipitação ao redor do tronco, sendo favorável à planta, principalmente, nos períodos menos chuvosos.

O processo de interceptação não ocorreu apenas nas copas do estrato superior, mas também nos estratos inferiores, que distribui mais lentamente a água de chuva interceptada em direção ao solo. O volume de água escoada pelo sub-bosque apresentou valor médio quatro vezes acima do escoado pelas árvores do estrato superior. $\mathrm{O}$ valor absoluto do escoamento pelo sub-bosque aumentou à medida que também aumentaram os valores da precipitação incidente sobre a cobertura vegetal.

Tabela 2 - Partição das chuvas durante o período de estudo Table 2 - Rainfall partitioning during the study tim

\begin{tabular}{lcccccc}
\hline & P T & PI & Esc Tr & Esc SB & PE & I \\
\hline $\mathrm{mm}$ & 1640 & 1392,4 & 6,6 & 32,8 & 1431,7 & 208,3 \\
$\%$ & 100 & 84,9 & 0,4 & 2,0 & 87,3 & 12,7 \\
\hline
\end{tabular}


Este estudo revelou perdas por interceptação florestal bastante acentuada nas menores classes de chuva. A Tabela 3 ilustra a variabilidade da interceptação média em diferentes intervalos de classe.

A interceptação foi inversamente proporcional à altura da chuva, ou seja, à medida que a altura da chuva aumentou, a interceptação diminuiu. Isso se deve ao fato de que as chuvas de alta magnitude contribuem para um maior umedecimento da vegetação, resultando em menores perdas. Vale salientar que a região é caracterizada por apresentar chuvas de alta magnitude e curta duração, e essa associação favorece a entrada de água no ecossistema, pois a evaporação ocorre já do início da chuva e se prolonga com sua duração, e a alta energia cinética das gotas impulsiona as folhas e ramos, provocando maior turbulência e, consequentemente, dificultando a retenção da chuva na copa. Esses resultados também foram observados por Llorens et al. (1997), Nalon e Vellardi (1993) e Molicová e Hubert (1994).

Através do coeficiente angular das equações de regressão das Figuras 5, 6 e 7, pode-se observar a capacidade de retenção do dossel vegetativo, tronco e sub-bosque. Os valores obtidos foram de 4,9, 8,3 e 7,3 mm, respectivamente.

Arcova et al. (2003), Oliveira Junior e Dias (2005) e Lima (1998) apresentaram valores inferiores de precipitação total médios capaz de gerar precipitação interna, sendo estes iguais a, respectivamente, 0,62 , 1,28 e 1,41 mm. Com relação ao escoamento pelo tronco, apenas Arcova et al. (2003) apresentaram resultado semelhante $(6,96 \mathrm{~mm})$ ao obtido nesse estudo. Valores superior $(11,34 \mathrm{~mm})$ e inferior $(4,14 \mathrm{~mm})$ foram apresentados por Oliveira Junior e Dias (2005) e Lima (1998), respectivamente.

Vários fatores contribuíram para que a precipitação total média necessária para gerar precipitação interna fosse maior que a apresentada pelos demais autores, inclusive a percentagem da área estudada coberta pelas árvores, pois a precipitação interna também é resultado das gotas de chuva que atingem o solo diretamente sem interagir com a cobertura vegetal. No entanto, a percentagem de área coberta pelas árvores é um dos fatores determinantes da quantidade de água de chuva que atinge o solo diretamente, podendo afetar, consequentemente, a dinâmica do escoamento superficial que atinge a rede hidrológica e o processo de infiltração que favorece os lençóis subterrâneos. Então, locais onde chuvas de pequena magnitude geram precipitação interna nem sempre oferecem melhores contribuições hídricas quando comparados com outras áreas onde o início da precipitação interna se dá após uma chuva de maior magnitude.

Verificou-se que chuvas com mesma altura em épocas distintas produziram resultados diferentes. Diversos fatores podem ter influenciado esses resultados, entre os quais podem ser citadaos as condições climáticas, as intensidade das chuvas e o intervalo entre as chuvas. Neal et al. (1993), citados por Lima (1998), constataram que a partição da precipitação em uma cobertura florestal não pode ser considerada proporção constante da precipitação do local durante todo o ano.

Tabela 3 - Interceptação média (\%) em diferentes intervalos de chuva

Table 3-Medium interception (\%) for different rainfall intervals

\begin{tabular}{cc}
\hline Classe de Chuva $(\mathrm{mm})$ & Interceptação $(\%)$ \\
\hline $0-10$ & 68 \\
$10-50$ & 25 \\
$50-70$ & 8 \\
$>70$ & 6 \\
\hline
\end{tabular}

\section{CONCLUSÃO}

A interceptação das chuvas obtida pela cobertura florestal foi de $208,3 \mathrm{~mm}$, correspondendo a $12,7 \%$ da precipitação total.

A precipitação efetiva foi de $1.431,7 \mathrm{~mm}$, equivalente a $87,3 \%$ da precipitação total, sendo particionada em $1.392,4 \mathrm{~mm}$ de precipitação interna, $6,6 \mathrm{~mm}$ de escoamento pelo tronco e $32,8 \mathrm{~mm}$ de escoamento pelo sub-bosque, correspondendo a $84,9 \%, 0,4 \%$ e $2,0 \%$, respectivamente.

A capacidade de retenção do dossel vegetativo, tronco e sub-bosque foi de 4,$9 ; 8,3$; e 7,3 mm, respectivamente.

\section{AGRADECIMENTOS}

Ao Conselho Nacional de Desenvolvimento Científico e Tecnológico (CNPq/CT-Hidro/UFRPE) e à administração do Horto de Dois Irmãos.

\section{REFERÊNCIAS}

ARCOVA, F. C. S. et al. Precipitação efetiva e interceptação das chuvas por floresta de mata atlântica em uma microbacia experimental em Cunha, São Paulo. Revista Árvore, v.27, n.2, p.257-262, 2003.

R. Árvore, Viçosa-MG, v.33, n.3, p.461-469, 2009 
BEGA, R. M. et al. Variabilidade espacial das precipitações pluviais diárias em uma estação experimental, em pindorama, SP. Bragantia, v.64, n.1, p.149-156, 2005.

CAMARGO, M. B. P.; HUBBARD, K. G. Spatial and temporal variability of daily weather variables in sub-humid and semiarid areas of the United States high plains. Agricultural and Forest Meteorology, v.93, n.2, p.141-148, 1999.

CASTRO, P. S. et al. Interceptação da chuva por mata natural secundária na região de Viçosa, MG. Revista Árvore, v.7, n.1, p.76-89, 1983.

DIETZ, J. et al. Rainfall partitioning in relation to forest structure in differently managed montane forest stands in Central Sulawesi, Indonesia. Forest Ecology and Management, v.237, n.1/3, p.170-178, 2006.

FERREIRA, S. J. F.; LUIZÃO, F. J.; DALLAROSA, R. L. G. "Precipitação interna e interceptação da chuva em floresta de terra firme submetida à extração seletiva de madeira na Amazônia Central". Revista Acta Amazônica, v.35, n.1, p.55-62, 2005.

GASH, J. H. C.; LLOYD, C. R.; LACHAUD, G. Estimating sparse forest rainfall interception with an analytical model. Journal of Hydrology, v. 170, n.1, p.79-86, 1995.

HUBER, A. M.; OYARZÚN, C. E. Redistribución de las precipitaciones en un bosque siempreverde del sur de Chile. Turrialba, v.42, n.22, p.192199, 1992.

JETTEN, V. G. Interception of tropical rain forest: performance of a canopy water balance model. Hydrology Process, v.10, n.5, p.671-85, 1996.

JIMÉNEZ, M. S. et al. Laurel forests in Tenerife, Canary Islands: the annual course of sap flow in Laurus trees and stand. Journal of Hydrology, v.183, n.3/4, p.307-321, 1996.

KELLMAN, M.; ROULET, N. Stemflow and throughfall in a tropical dry forest. Earth Surface Processes Landforms, v.15, n.1, p.55-61, 1990.

R. Árvore, Viçosa-MG, v.33, n.3, p.461-469, 2009
INSTITUTO NACIONAL DE METEOROLOGIA INMET. Normais Climatológicas (1961 1990). Brasília: SPI/Embrapa, 1992. 84p.

LEOPOLDO, P. R.; CONTE, M. L. Repartição da água de chuva em cobertura vegetal com características de cerradão. In: SIMPÓSIO BRASILEIRO DE HIDROLOGIA E RECURSOS HÍDRICOS E SIMPÓSIO INTERNACIONAL DE RECURSOS HIIDRICOS EM REGIÕES METROPOLITANAS, 6., 1985, São Paulo. Anais... São Paulo: ABRH, 1985. v.3. p.212-220.

LIMA, P. R. A. Retenção de água de chuva por mata ciliar na região central do estado de São Paulo. 1998. 186f. Dissertação (Mestrado emAgronomia) Universidade Estadual Paulista, Botucatu, 1998.

LLORENS, P. et al. Rainfall interception by a Pinus sylvestris forest patch overgrown in a Megiterranean mountainous abandoned area I. Monitoring design and results down to the event scale. Journal of Hydrology, v.199, n.3, p.331-345, 1997.

MARIN, C. T.; BOUTEN, W.; SEVINK, J. Gross rainfall and its partitioning into throughfall, stemflow and evaporation of intercepted water in four forest ecosystems in western Amazonia. Journal of

Hydrology, v.237, n.1, p.40-57, 2000.

MOLICOVÁ, H.; HUBERT, P. Canopy influence on rainfall fields' microscale struture in tropical forests. Journal Applied Meteorology, v.33, NUMERO, p.1464-1467, 1994.

NALON, M. A.; VELLARDI, A. C. V. Estudo do balanço hídrico nas escarpas da serra do mar, região de Cubatão, SP. Revista do Instituto Florestal, v.5, n.1, p.39-58, 1993.

NEAL, C. et al. Hydrological impacts of hardwood plantation in lowland Britain: preliminary findings on interception at a forest edge, Black Wood, Hampshire, Southern England. Journal of Hydrology, v.127, n.1/4, p.349-65, 1991.

OLIVEIRA JÚNIOR, J.C.; DIAS, H. C. T. Precipitação efetiva em fragmento secundário da mata atlântica. Revista Árvore, v.29, n.1, p.9-15, 2005.

R. Árvore, Viçosa-MG, v.33, n.3, p.461-469, 2009 
RUTTER, A. J.; MORTON, A. J.; ROBINS, P. C. A predictive model of rainfall interception in forests, II. Generalization of the model and comparison with observations in some coniferous and hardwood stands. Journal of Applied Ecology, v.12, p.367-384, 1975.

SILVESTRE,A. N.; CARVALHO, P.V.van den BERG, C. Bacia do Prata: Aspectos qualitativos da água. In: MACHADO, I.; LOPES, A.; PORTO, K. (Eds.).

Reserva ecológica de Dois Irmãos: Estudos em um remanescente de Mata Atlântica em área urbana. Recife, Universitária UFPE, 1998. p.51-64. van DIJK, A. I. J. M.; BRUIJNZEEL, L. A. Modelling rainfall interception by vegetation of variable density using an adapted analytical model. Part 1 . Model description. Journal of Hydrology, v. 247, n.3, p.230-238, 2001.

ZHANG, G. et al. Modeling and measurement of two-layercanopy interception loss in a subtropical evergreen forest of central-south China. Hydrology and Earth System Sciences, v.10, n.1, p.65-77, 2006. 
